\title{
COMPARISON BETWEEN AN OPHTHALMIC OPTICIAN AND AN OPHTHALMOLOGIST IN SCREENING FOR DIABETIC RETINOPATHY
}

\author{
C. J. HAMMOND, J. SHACKLETON, D. W. FLANAGAN, J. HERRTAGE and J. WADE \\ Cambridge
}

\begin{abstract}
SUMMARY
The best method of screening for diabetic retinopathy is still debated: fundus photography, general practitioners, hospital physicians and ophthalmic opticians have been advocated. This study compared the performance of an ophthalmic optician with an ophthalmologist, both using mydriatic and slit lamp biomicroscopy and direct ophthalmoscopy. A total of 474 eyes of diabetics in a single group practice were examined by both practitioners at their annual check. There was total agreement about presence or absence of retinopathy in 366 eyes $(\mathbf{7 7 \%})$. Although the optician diagnosed less background diabetic retinopathy $(83$ versus 123 eyes) and diabetic maculopathy (47 eyes versus 63 eyes), he would have referred 20 of 26 eyes with moderate or severe maculopathy and 33 of 36 eyes with moderate or severe background retinopathy: sensitivities of 0.77 and 0.92 respectively. This compares favourably with previous studies and we suggest that ophthalmic opticians with suitable training would be an effective body to screen for diabetic retinopathy.
\end{abstract}

The Saint Vincent Declaration, signed in October 1989 under the aegis of the World Health Organization and the International Diabetes Federation, declared a five year target to 'elaborate, initiate and evaluate comprehensive programmes for detection and control of diabetes and of its complications' in order to reduce new blindness by one-third. ${ }^{1}$ Diabetes is the cause of as many as 4000 new cases of blindness in the United States each year and is the leading cause of new blindness in working age adults there, ${ }^{2}$ and it has been estimated that screening and treatment (even with current suboptimal care) of type II diabetics saves the United States government

From: Addenbrooke's Hospital, Cambridge, UK.

Correspondence to: Mr C. J. Hammond, MRCP, FRCOphth, Department of Ophthalmology, St Thomas' Hospital, Lambeth Palace Road, London SE1 7EH, UK.
$\$ 247$ million per year. ${ }^{3}$ Diabetes is also the commonest cause of blind registration in adults aged 20-65 years in the United Kingdom, and similarly screening programmes can be demonstrated to be cost-effective.

There is no consensus on the best method of screening, and studies have evaluated communitybased non-mydriatic polaroid fundus photography, ${ }^{4-9}$ non-mydriatic hospital-based fundus photography, ${ }^{10,11}$ hospital-based mydriatic fundus photography, ${ }^{12}$ hospital diabetic physicians, health care workers and general practitioners ${ }^{13-18}$ and ophthalmic opticians, ${ }^{19-21}$ as well as other tests such as tritan discrimination sensitivity. ${ }^{22}$ This study aimed to compare the performance of an ophthalmic optician with that of an ophthalmology clinical assistant in the detection of diabetic retinopathy requiring referral in a group of diabetic patients from a single group practice.

\section{SUBJECTS AND METHODS}

A group practice in Ely, Cambridgeshire, was chosen for this study. The population base was a mix of rural and town dwellers, and the practice covers a population of 15800 . A total of 349 diabetic patients were identified $(2.17 \%)$ from a review of the practice database. These patients were informed that their eyes would be examined by an experienced clinical assistant in ophthalmology (J.H.) at their annual examination, and at the same time were asked to visit the participating ophthalmic optician (J.W.). Of these patients, 237 (68\%) were examined by both practitioners independently using pupillary dilatation ( $1 \%$ cyclopentolate) and direct ophthalmoscopy, slit lamp biomicroscopy using a 78 dioptre lens and indirect ophthalmoscopy where appropriate. The examinations were carried out in the community in the GP practice or the optician's shop. The majority of patients were seen by both examiners within a few

Eye (1996) 10, 107-112 (C) 1996 Royal College of Ophthalmologists 
hours, although a few examinations were separated by a few days; all patients were examined within 2 weeks by both practitioners. Thirty-five patients were examined only by the ophthalmologist and did not attend the optician despite reminders (most patients citing loyalty to their own optician as the reason). These patients are not included in the analysis.

The examiners were asked to classify eyes into background retinopathy (BDR) and diabetic maculopathy (MP). BDR was divided into mild, moderate and severe, with the latter two being indications for referral to a hospital diabetic retinopathy clinic if not already under ophthalmological review. Severe BDR changes were graded if proliferative retinopathy or pre-proliferative retinopathy were present. Patients were classified as having moderate BDR if, in addition to background changes of microaneurysms, dot haemorrhages and hard exudates, there were deeper blot haemorrhages. MP was divided into minimal, moderate or severe. Minimal MP described any diabetic retinopathy within the temporal arcades, moderate MP was present if there were areas of retinal oedema or hard exudates within two disc diameters of the fovea, and a classification of severe MP was given if the macular oedema or retinopathy directly involved the fovea. The examiners were asked to refer all moderate and severe MP to a hospital diabetic eye clinic if the patients were not under active ophthalmological follow-up. The groups requiring referral to hospital were described as having a sight-threatening condition: moderate or severe BDR or moderate or severe MP.

\section{RESULTS}

Of the 474 eyes examined by both ophthalmologist and optician, there was agreement about the presence or absence of any diabetic retinopathy and its grade in 366 eyes (77\%). Taking diabetic retinopathy of any sort, the optician found retinopathy in 92 eyes $(19 \%)$, and 11 of these were felt by the ophthalmologist to be normal (all were graded as mild BDR or minimal MP by the optician and therefore not in the referral group). The ophthalmologist diagnosed diabetic retinopathy in 132 eyes

Table I. Diagnosis of background diabetic maculopathy (BDR): comparison of the number of eyes diagnosed by an ophthalmologist and an optician

\begin{tabular}{lcc}
\hline Severity & Ophthalmologist & Optician \\
\hline Mild & 87 & 50 \\
& $(19 \%)$ & $(11 \%)$ \\
Moderate & 24 & 29 \\
& $(5 \%)$ & $(6 \%)$ \\
Severe & 12 & 4 \\
& $(3 \%)$ & $(0)$ \\
Total & 123 & 83 \\
& $(26 \%)$ & $(18 \%)$ \\
\hline
\end{tabular}

Figures in parentheses are the percentage of the total eyes examined.
$(28 \%)$. Fifty-five of these were described as normal by the optician; the ophthalmologist graded 53 of these mild BDR and/or minimal MP, but 2 eyes were described as having moderate BDR by the ophthalmologist and so referred for consideration of laser treatment.

Tables I and II illustrate the gradings applied by the ophthalmologist and optician for BDR and MP respectively. The ophthalmologist described BDR in 123 eyes $(26 \%)$ and the optician in 83 eyes (18\%). Of these patients, both screeners agreed on 73 eyes. The ophthalmologist categorised 49 eyes classed as normal by the optician as having BDR: 47 with mild BDR, and 2 with moderate BDR (and therefore in the referral category). The optician described 11 eyes as having mild BDR, 10 of which the ophthalmologist classed as normal and 1 as moderate $\mathrm{BDR}$ and therefore eligible for referral. Of the 12 severe BDR cases classified by the ophthalmologist, the optician described 4 of these as severe and 8 as moderate: all would have therefore been referred to a diabetic eye clinic. A comparison of the ophthalmologist's and optician's findings is illustrated in Figs. 1 and 2. Of these severe BDR eyes, 10 were already attending a hospital eye clinic and the remaining 2 were referred. The optician would not have referred 3 eyes which the ophthalmologist did refer to the hospital eye service for BDR.

The optician described 45 eyes $(9 \%)$ as having MP and the ophthalmologist 63 eyes $(13 \%)$. Both agreed on the MP grading for 41 eyes. The remaining 4 eyes graded by the optician as minimal MP were found to have no MP by the ophthalmologist. Twenty-one eyes were graded as normal by the optician but as having MP by the ophthalmologist: 20 of these eyes were graded as minimal MP but 1 was graded as moderate MP by the ophthalmologist, requiring referral to the diabetic eye clinic. In 1 patient the ophthalmologist reported severe MP in both eyes whilst the optician diagnosed drusen. In addition, of the 25 eyes described by the optician as having minimal MP, 3 were found to have severe MP by the ophthalmologist. Figs. 3 and 4 illustrate the findings with regard to maculopathy. There was therefore a

Table II. Diagnosis of diabetic maculopathy (MP): comparison of the number of eyes diagnosed by an ophthalmologist and an optician

\begin{tabular}{lcc}
\hline Severity & Ophthalmologist & Optician \\
\hline Minimal & 35 & 25 \\
& $(7 \%)$ & $(5 \%)$ \\
Moderate & 14 & 14 \\
Severe & $(3 \%)$ & $(3 \%)$ \\
& 12 & 6 \\
Total & $(3 \%)$ & $(0)$ \\
& 63 & 45 \\
& $(13 \%)$ & $(9 \%)$ \\
\hline
\end{tabular}

Figures in parentheses are the percentage of the total eyes examined. 


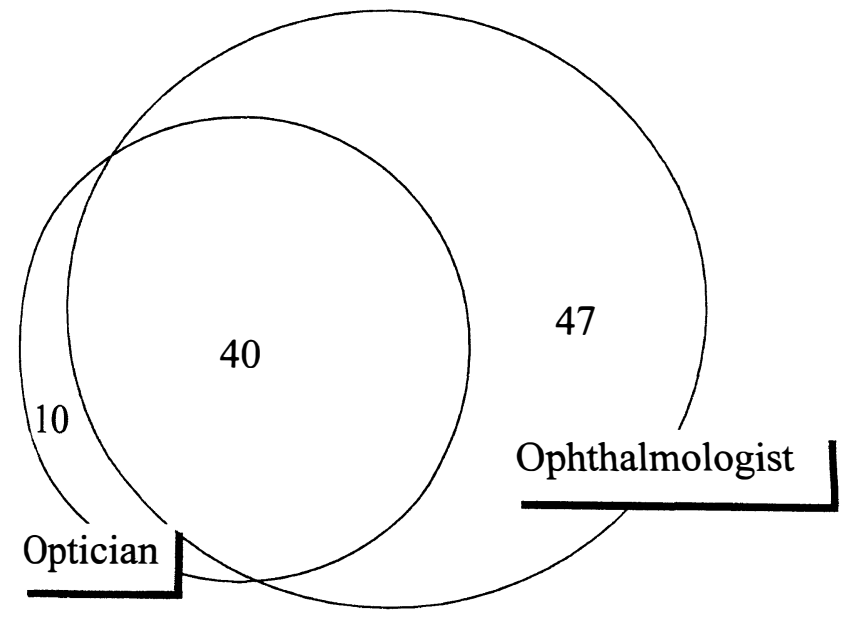

Ophthalmologist Optician

Background Retinopathy

$123 \quad 83$

Mild BDR

$87 \quad 50$

Fig. 1. Diagnosis of mild background retinopathy (BDR) by an ophthalmologist and an optician.

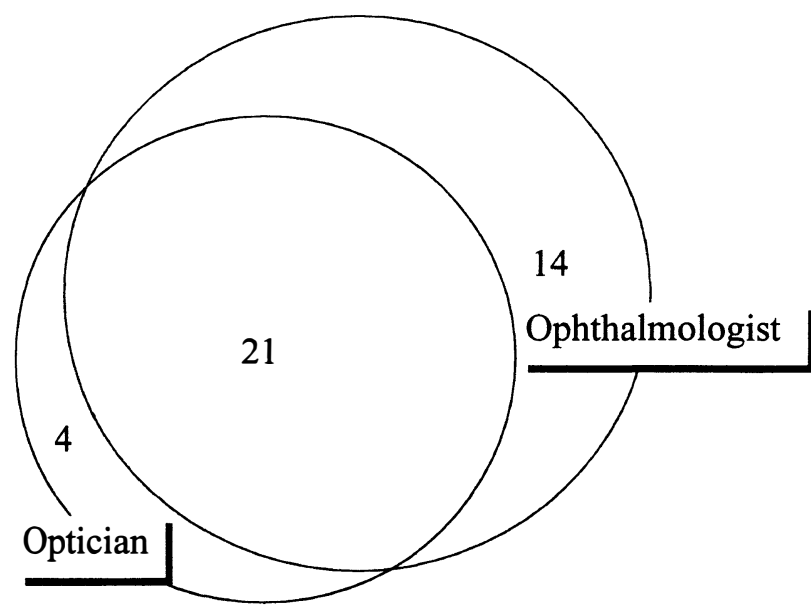

Ophthalmologist Optician

$\begin{array}{lll}\text { Diabetic Maculopathy (MP) } & 63 & 45 \\ & 35 & 25\end{array}$

Fig. 3. Diagnosis of minimal diabetic maculopathy (MP) by an ophthalmologist and an optician.

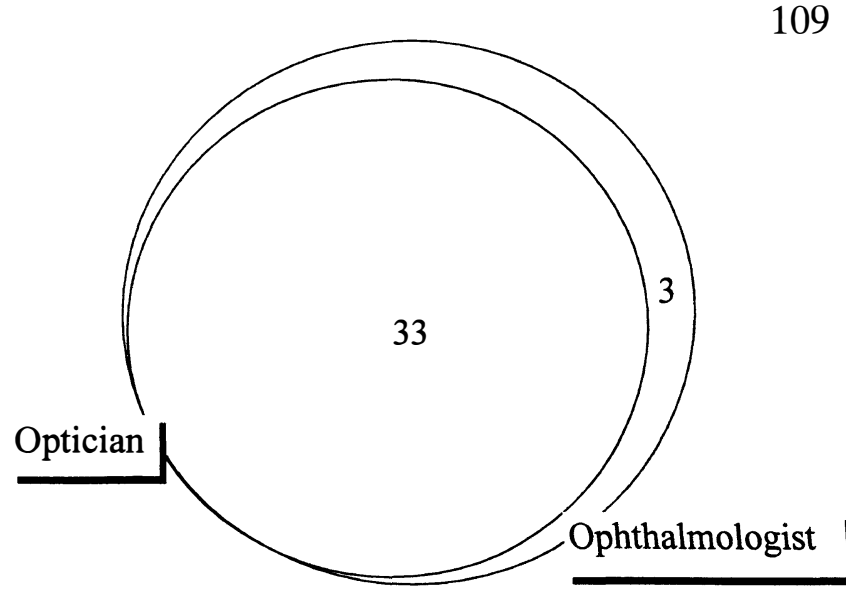

Ophthalmologist Optician

Background Retinopathy $\quad 123 \quad 83$

Moderate or Severe BDR $\quad 36 \quad 33$

2 eyes with moderate BDR diagnosed normal by optician

1 eye with moderate BDR diagnosed mild BDR by optician

i.e. the optician would not have referred 3 eyes to hospital clinic

Fig. 2. Diagnosis of moderate or severe background retinopathy $(B D R)$ by an ophthalmologist and an optician.

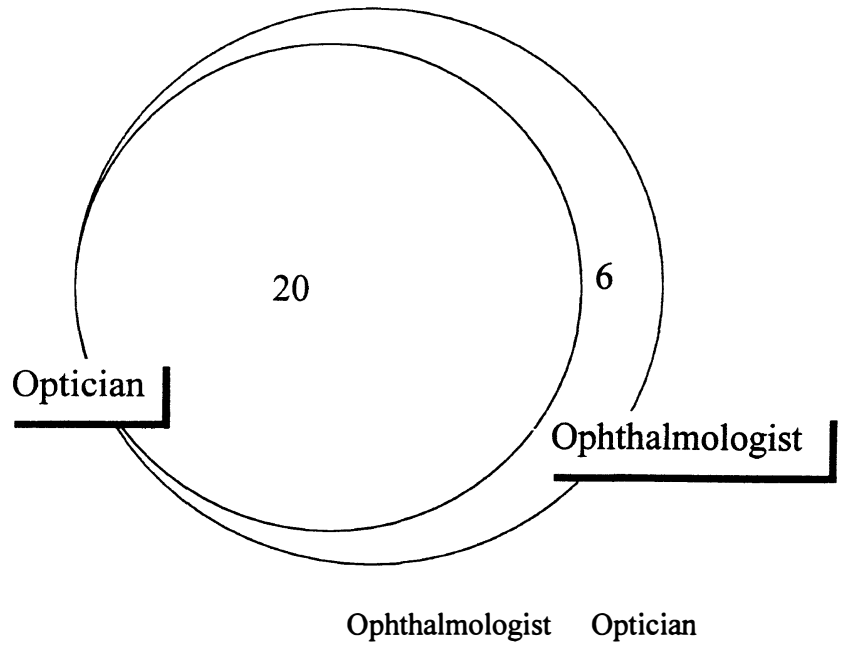

$\begin{array}{lll}\text { Diabetic Maculopathy (MP) } & 63 & 45 \\ \text { Moderate or Severe MP } & 26 & 20\end{array}$

1 eye with moderate MP diagnosed normal by optician 3 eyes with severe MP diagnosed minimal MP by optician 2 eyes with severe MP diagnosed as drusen by optician

i.e. the optician would not have referred 6 eyes to hospital clinic

Fig. 4. Diagnosis of moderate or severe diabetic maculopathy (MP) by an ophthalmologist and an optician. 
significant difference in terms of patients requiring referral for hospital intervention in 6 eyes of 4 patients with maculopathy.

Nine of the patients had received laser photocoagulation in a total of 16 eyes (4\% of those examined). Eighteen patients (8\%) attended a hospital diabetic eye clinic already. Ten patients from this screening study were referred to the diabetic eye clinic: both screeners referred 7 of the cases; 3 patients would not have been referred to the hospital eye service by the optician.

\section{DISCUSSION}

The case for developing a screening programme for diabetic retinopathy is overwhelming. Diabetic retinopathy fulfils the agreed criteria of a disease which is suitable to screen for $^{23}$ in that it is an important public health problem causing significant morbidity which has a recognisable latent or presymptomatic stage. There exists treatment which is not only effective at reducing blindness but also acceptable to patients and universally applied by ophthalmologists around the world. There is cost-benefit analysis to suggest that not only does screening and early treatment benefit the economy by reducing the burden of costs of caring for blind people, but also that patients treated continue to remain economically active within the community. Finally, there exist screening tests which are acceptable to patients and professionals alike. However, there is no clear consensus as to the best method of screening in diabetic retinopathy.

The 'gold standard' applied to screening for diabetic retinopathy is seven-field stereo fundus photography or fluorescein angiography, but neither of these is practical as a screening tool. ${ }^{24}$ Although fundus examination by a consultant ophthalmologist can be used as a practical standard, it is obvious that in the United Kingdom (and other countries) both limited numbers of ophthalmologists and the structure of the health care system (in which there is no open access) mean that this group cannot be used to screen for diabetic retinopathy. ${ }^{25}$ Even where there are adequate ophthalmologists and general access for the diabetic population, there is a low attendance rate: a study in Nova Scotia found less than $10 \%$ of diabetic patients under the age of 50 years were examined. ${ }^{26}$

Screening needs to be community-based in order to improve compliance, and accepted wisdom holds that high compliance is essential for a screening programme to be successful. ${ }^{27}$ However, it is not enough to have a screening facility within the community: patients need to be actively recruited and preferably given a specific appointment for screening (in breast cancer screening, it has been shown that a higher compliance rate is achieved with set appointments rather than open invitations ${ }^{28}$ ). A study of patients registered blind due to diabetic retinopathy showed that $50 \%$ had no screening despite being known to be diabetic. ${ }^{29}$ Barrie et al..$^{30}$ in Glasgow demonstrated that, despite a concerted campaign to recruit patients within a well-circumscribed population, only $8 \%$ of predicted diabetic patients attended a community-based optometric fundal examination. The general practitioner (GP) lists are the best register of diabetic patients in this country, and with increasing computerisation of practices and establishment of databases to achieve other screening targets, these should be used in conjunction with the screening programme to optimise compliance.

The majority of presbyopic patients consult an optician, and this could be an important way of improving take-up rates of any screening programme. Our response rate of $68 \%$ in this study was reasonable, and suggests that a screening programme run in conjunction with a GP practice (or, preferably, at the same time as a GP's diabetic clinic if he or she runs one) would have a good compliance.

The sensitivity of any screening test is most important, as the cost of false negatives, i.e. of missing patients who require laser therapy, is expensive. In this study the sensitivity of the optometrist in comparison with the ophthalmologist was 0.92 in the detection of sight-threatening background diabetic retinopathy (moderate or severe classifications in our series) and 0.77 in the detection of sight-threatening maculopathy (moderate or severe classifications in our series). These figures compare favourably with other reported screening methods. The specificity of detection of false positive referrals to the hospital eye unit (less important but contributing to the cost-effectiveness of any programme) was 1.0 for the optician in this study: he referred no patients to the hospital eye service which the ophthalmologist did not. Therefore we have found in this study that a well-motivated and trained optician is effective at screening for diabetic retinopathy, and demonstrates remarkable concordance with an ophthalmology clinical assistant. Obviously research would be required to see whether by suitable training, motivation and maintenance of skills, this could be extended to opticians in general.

The cost-effectiveness of any screening method needs to be taken into account, as the choice of method depends on achieving the lowest cost per true positive at acceptable levels of sensitivity and specificity. Costs are difficult to estimate, but one study suggested significant variation between areas of the United Kingdom and methods: $£ 441-£ 609$ for clinical assistants, $£ 784$ for ophthalmic opticians, $£ 1033$ for hospital physicians and £497-£1159 for 
photography. All these figures were costs per true positive case detected. ${ }^{31}$ In our study, we have assumed that costs to the patient of visiting each examiner are the same, as they were both located within a few hundred metres of each other within the community. The cost in examiner's fee can be estimated in our study: the clinical assistant received $£ 56$ per session and saw an average of 10 patients per session, while the optician received $£ 13$ per patient seen, under the current agreement with the Family Health Service Authorities (although opticians would probably request more in a formal screening service). Although the overhead costs of the optician's facility on a main shopping street are likely to be more expensive than those in a GP practice, it must be borne in mind that opticians are already established in the community with appropriate equipment for fundal examination while few GP practices have room or equipment for ophthalmic examination by a clinical assistant in ophthalmology, and so the costs incurred in setting up a screening service would be much higher if the latter were performing the screening.

It has been shown that the cost per true positive for fundal camera screening falls with increasing throughput (up to about 1200 patients screened per annum). ${ }^{31}$ The optician involved in this study (J.W.) estimates that he sees 500 patients per year. Opticians would need regular training (presumably by consultant ophthalmologists) and regular updates as well as having a regular throughput in order to maintain their diagnostic skills. Unlike a clinical assistant or mobile camera in a GP practice, who might be underutilised if there was a poor attendance, opticians would have their normal practice to undertake. If ophthalmic opticians were to agree to perform screening for diabetic retinopathy, they would certainly ask for a higher fee than the simple $£ 15$ refraction fee currently given, and indeed careful dilated fundoscopy in addition to refraction would take longer than their normal consultation. However, the costs must be cheaper than setting up a totally 'new' screening service with additional personnel and buildings and equipment costs. However, commitment would be required in terms of money from either purchasers or central government.

\section{CONCLUSION}

There are already established guidelines on the requirements for screening for diabetic retinopathy in both Europe ${ }^{32}$ and the United States. ${ }^{33}$ We believe that ophthalmic opticians would be a suitable body to carry out this screening, as they are suitably trained, community-based, already consulted by a large proportion of elderly diabetic patients, and with training can develop appropriate diagnostic skills. However, any screening programme would have to be set up with the assistance of general practitioners, who have the demographic data vital to achieving reasonable compliance rates.

Key words: Diabetic retinopathy, Optician, Screening.

\section{REFERENCES}

1. WHO/IDF Europe. Diabetes and research in Europe: the St Vincent declaration. Diabetes Med 1990;7:360.

2. Anonymous. Public health focus: prevention of blindness associated with diabetic retinopathy. MMWR Morb Mortal Wkl Rep 1993;42:191-5.

3. Javitt JC, Aiello LP, Chiang Y, Ferris FL, Canner JK, Greenfield S. Preventive eye care in people with diabetes is cost-saving to the federal government: implications for health-care reform. Diabetes Care 1994;17:909-17.

4. Leese GP, Ahmed S, Newton RW, Jung RT, Ellingford A, Baines P, Roxburgh S, Coleiro J. Use of mobile screening unit for diabetic retinopathy in rural and urban areas. BMJ 1993;306:187-9.

5. Foulds WS, MacCuish AC, Barrie T, et al. Diabetic retinopathy in the West of Scotland: its detection and prevalence, and the cost-effectiveness of a proposed screening programme. Health Bull (Edinb) 1983;41: 318-26.

6. Peters AL, Davidson MB, Ziel FH. Cost-effective screening for diabetic retinopathy using a nonmydriatic retinal camera in a prepaid health-care setting. Diabetes Care 1993;16:1193-5.

7. Taylor R, Lovelock L, Tunbridge WM, Alberti KG, Brackenridge RG, Stephenson P, Young E. Comparison of non-mydriatic retinal photography with ophthalmoscopy in 2159 patients: mobile retinal camera study. BMJ 1990;301:1243-7.

8. Heaven CJ, Cansfield J, Shaw KM. The quality of photographs produced by the non-mydriatic fundus camera in a screening programme for diabetic retinopathy: a 1 year prospective study. Eye 1993;7:787-90.

9. Wareham N, Greenwood R. Screening for diabetic retinopathy using non-mydriatic fundus photography. Diabetic Med 1991;8:607-8.

10. Jones D, Dolben J, Owens DR, Vora JP, Young S, Creagh FM. Non-mydriatic Polaroid photography in screening for diabetic retinopathy: evaluation in a clinical setting. BMJ 1988;296:1029-30.

11. Pugh JA, Jacobson JM, van Heuven WA, Watters JA, Tuley MR, Lairson DR, et al. Screening for diabetic retinopathy: the wide-angle retinal camera. Diabetes Care 1993;16:889-95.

12. Moss EM, Klein R, Kessler SD, Richie KA. Comparison between ophthalmoscopy and fundus photography in determining severity of diabetic retinopathy. Ophthalmology 1985;92:62-7.

13. Buxton MJ, Sculpher MJ, Ferguson BA, Humphreys JE, Altman JFB, Spiegelhalter DJ, et al. Screening for treatable diabetic retinopathy: a comparison of different methods. Diabetic Med 1991;8:371-7.

14. Forrest RD, Jackson CA, Yudkin JS. Screening for diabetic retinopathy: comparison of a nurse and a doctor with retinal photography. Diabetes Res 1987;5: 39-42.

15. Sullivan FM, Stearn R, MacCuish AC. The role of general practitioners in diabetic eye care in Lanarkshire. Diabetic Med 1994;11:583-5.

16. Reenders K, de Nobel E, van den Hoogen H, van Weel C. Screening for diabetic retinopathy by general 
practitioners. Scand J Primary Health Care 1992;10: 306-9.

17. Griffith, SP, Freeman WL, Shaw CJ, et al. Screening for diabetic retinopathy in a clinical setting: a comparison of direct ophthalmoscopy by primary care physicians with fundus photography. $J$ Fam Practice 1993;37:49-56.

18. Sussman EJ, Tsiaras WG, Soper KA. Diagnosis of diabetic eye disease. JAMA 1992;247:3231-4.

19. Hill RD. Screening for diabetic retinopathy at primary health care level. Diabetologica 1981;20:670.

20. Burns-Cox CJ, Dean Hart JC. Screening of diabetics for retinopathy by ophthalmic opticians. BMJ 1985;290: $1052-4$.

21. Kleinstein RN, Roseman JM, Herman WH, Holcombe J, Louv WC. Detection of diabetic retinopathy by optometrists. J Am Optom Assoc 1987;58:879-82.

22. Tregear SJ, Ripley LG, Knowles PJ, Gilday RT, de Alwis DV, Reffin JP. Automated tritan discrimination sensitivity: a new clinical technique for the effective screening of severe diabetic retinopathy. Int J Psychophysiol 1994;16:191-8.

23. Wilson JMG, Jungner G. The principles and practice of screening for disease. Public health papers 34. Geneva: WHO, 1968.

24. Singer DE, Nathan DM, Fogel HA, Schachat AP. Screening for diabetic retinopathy. Ann Intern Med 1991;116:660-71.
25. MacCuish AC. Early detection and screening for diabetic retinopathy. Eye 1993;7:254-9.

26. Begg IS. Screening for diabetic retinopathy: changes in direction? Can J Ophthalmol 1993;28:3-4.

27. Torgerson DJ, Donaldson C. An economic view of high compliance as a screening objective. BMJ 1994; 308:117-9.

28. Williams EMI, Vessey MP. Randomised trial of two strategies offering women mobile screening for breast cancer. BMJ 1989;299:158-9.

29. Clark JB, Grey RH, Lim KK, Burns-Cox CJ. Loss of vision before ophthalmic referral in blind and partially sighted diabetics in Bristol. Br J Ophthalmol 1994; 78:741-4.

30. Barrie T, Bronte-Stewart J, MacCuish A, Kirkness C. The role of optometrists in the screening for diabetic eye disease in the community. Poster at Royal College of Ophthalmologists meeting, Birmingham, 1995.

31. Sculpher MJ, Buxton MJ, Ferguson BA, et al. A relative cost-effectiveness analysis of different methods of screening for diabetic retinopathy. Diabetic Med 1991;8:644-50.

32. Retinopathy Working Party. A protocol for screening diabetic retinopathy in Europe. Diabetic Med 1991; $8: 263-7$.

33. American Academy of Ophthalmology. Quality of Care Committee, Retina Panel. Diabetic retinopathy: preferred practice pattern. San Francisco: American Academy of Ophthalmology, 1989. 